\title{
Knowledge disagreement formulations in problem-based learning tutorials: balancing pedagogical demands with 'saving face'
}

\author{
Robert McQuade*a, Sally Wiggins $^{\mathrm{b}}$, Esther Ventura-Medina $^{\mathrm{a}}$, Tony Anderson ${ }^{\mathrm{c}}$ \\ ${ }^{a}$ Department of Chemical and Process Engineering, University of Strathclyde, Glasgow \\ ${ }^{b}$ Department of Behavioural Science and Learning, Linköping University, Sweden \\ ${ }^{c}$ School of Psychological Sciences and Health, University of Strathclyde, Glasgow
}

Full correspondence details for the * corresponding author:

Robert McQuade, r.m.mcquade@ @strath.ac.uk, James Weir Building, Department of Chemical and Process Engineering, University of Strathclyde, 75 Montrose Street, Glasgow, UK, G1 $1 \mathrm{XJ}$

This project is funded by The Engineering and Physical Sciences Research Council Award (EPSRC Reference 1827113). The authors would like to thank the manuscript reviewers for their attention to detail and for such supportive comments throughout the publication process.

Keywords: conversation analysis; student interaction; tutorial learning; problem-based learning; disagreements

\begin{abstract}
As a pedagogical approach that aims to develop students' group-working skills and to challenge their current knowledge, problem-based learning (PBL) provides a unique setting in which to examine disagreements in interaction. Previous research on disagreements in classrooms have typically examined tutor-student interaction or student-student interaction in which a tutor is present. The current paper, however, examines tutorless PBL tutorials and focuses specifically on those moments in which knowledge claims are challenged by other students. The data comprise of 30 hours of video recordings from 24 chemical engineering PBL tutorials in a Scottish university. Conversation analysis was used to identify 101 disagreement formulations, many of which follow the format seen in other classroom settings (e.g. agreement-prefaced disagreements). A subset of disagreement formulations manage epistemic responsibility through invoking expert sources (e.g. tutor-provided worksheets and academically superior outgroup members). Through invoking an expert source in this way, students attend to the pedagogical activities - without tutor assistance - while minimising the conversational trouble associated with the act of 'doing' disagreement (i.e. indirectly enacting disagreements whilst maintaining a neutral stance). This paper thus contributes to CA literature on disagreements, while providing a unique insight into PBL tutorial interaction. Directions for future research are suggested.
\end{abstract}




\section{Introduction}

Claiming knowledge in a classroom setting can be a delicate interactional business. As

summarised by Stivers, Mondada and Steensig (2011), knowledge claims can involve the management of epistemic access (e.g. the source of the knowledge), epistemic primacy (e.g. who has the rights to know) and epistemic responsibility (e.g. who is accountable for the knowledge). When this knowledge management occurs within a pedagogical context that emphasises the role played by critical thinking and metacognition (Hmelo-Silver, 2004), this demands additional attention to the negotiation of conflicting knowledge stances, alongside maintaining one's stance as a group member. This study is situated within such a context, in which the pedagogical approach is problem-based learning (PBL), which expects students to challenge each other in order to encourage 'cognitive conflict', and to facilitate new learning (De Grave, Boshuizen \& Schmidt, 1996). What happens, then, when such knowledge is challenged or when one student disagrees with another? It is within this context that we examine how students manage the complex balance of enacting the pedagogical goals of knowledge generation, alongside social normative constraints around disagreements in conversation. This paper examines the different types of knowledge disagreement formulations used within problem-based learning (PBL) tutorials in higher education. In the rest of the introduction, we overview related conversation analytic work on disagreements and those in classroom settings before focusing specifically on the relevance of the PBL approach for knowledge management.

\section{Disagreements in the classroom}

The act of disagreement is a complex business, closely related to concepts such as conflicts (Edstrom, 2004; Hosoda \& Aline, 2015; Sifianou, 2012), reproaches (Tainio, 2011), oppositions (Angouri \& Locher, 2012) and arguments or disputes (Georgakopoulou, 2001), where there is a substantial degree of theoretical crossover. Likewise, while there is a rich and diverse literature on disagreements within cognitive, linguistic or social frameworks (e.g. Angouri \& Locher, 2012), the concern in this paper is on the sequential management of knowledge disagreements in tutorial interaction, and thus, it is within conversation analytic (CA) work that our research is most centrally located. Disagreements are typically understood in CA as a form of interactional transgression and analysed in terms of their consequences for sense-making in interaction (Sacks, 1987). They are often treated as dispreferred actions, in that they mark disaffiliation with another speaker, and as such, are often noticeable through the presence of pauses, preface markers and qualifying statements (Pomerantz, 1984a, b).

When considered within an educational setting, disagreements take on a particular pedagogical relevance (Angouri \& Locher, 2012). For instance, in her study of Finnish classroom interactions, Tainio (2011) showed how teachers accompany reproaches with displays of humour, supportive discourse, and by ensuring that no student is singled out during these episodes. The management of institutional power is a complex one (Benwell \& Stokoe, 2002), and even teachers must adhere to the expectations of conversational politeness if they are to avoid more serious disagreements; highly detrimental to both their alliances with, and in maintaining the engagement of, their students (Tainio, 2011).

Whilst classroom disagreements amongst younger children tend to be more readily expressed (Cekaite \& Björk-Willén, 2013; Niemi, 2014), Niemi (2014) also shows how 
children invoke pretend frames (e.g. intertwining elements of videogames with 'real life') as a conversational strategy during peer disputes, as well as demonstrating an awareness of the institutional moral order (e.g. what is, and what is not, appropriate). Numerous studies on disagreement have also examined the L2 classroom environment (e.g. Hüttner, 2014). As in the recent CA works of Hosoda and Aline (2015), with developing proficiency of English as a second language, individuals tended not to produce explicit disagreements, opting for a much subtler approach involving the use of disagreement prefaces, accounts and physical gestures. The findings from each of these studies underscore the interactional complexity of disagreements, and how 'doing' disagreement must be very sensitively managed if it is to adhere to the institutional bounds of the classroom setting (Leung, 2005).

Other work on student-student interaction in the classroom has considered issues such as how students request information or assistance from each other (Jakonen, 2015) or manage epistemic claims (Jakonen \& Morton, 2015). Waring (2001) demonstrated how students use 'peer referencing' (e.g. "as you said") to display affiliation, but also disagree with the other speaker. This can also be part of the strategies employed to resolve or exit from a disagreement. For instance, in the face of a disagreement deadlock, the use of 'asserting vulnerability' (e.g. "I'm really lost") can be a resource for strategically backing down from a disagreement when one's previous assertions have failed to gain any confirmation by other speakers (Waring, 2001). The tutor can also be invoked - either by the students, or through the tutor intervening themselves - as a means of resolving ongoing disagreements when there is a tutor present (Sharma, 2013). Another study by Sharma (2012) noted that students can use resources (such as tutor provided guidance documents) to validate arguments and enable an exit from a disagreement sequence.

\section{Disagreements and problem-based learning (PBL) pedagogy}

In contrast to work that examines related issues of epistemic management within tutor-student interaction (e.g. Kääntä, 2014; Koole, 2010, 2012; Macbeth, 2011; Sert, 2013), in PBL one member does not, however, a priori have greater epistemic primacy than another. PBL is a student-centred pedagogical approach within which students should learn not only about subjects and disciplines, but also the skills of working together in a group (Schmidt, 1993). It places 'problems' - ambiguous or open-ended case studies - at the centre of learning and is designed to enable students to develop effective problem-solving skills, and the capacity to learn (Hmelo-Silver, 2004). One of the underlying psychological principles of PBL is that it induces cognitive change in individuals: that there should be a mismatch between the students' knowledge and the problems to be solved (De Grave et al., 1996). The PBL tutorial then becomes the primary space in which alternative theories are discussed, and in combination with individual reading, this should be the stimulus for conceptual change. The tutor becomes a guiding figure rather than a direct knowledge source, and in some forms of PBL, the tutor is not present at every tutorial. Central to PBL, then, is the group discussion and the way in which students - sometimes without a tutor present - manage different knowledge stances regarding problem on which they are focused.

One of the argued benefits of PBL is that it should enable students to develop group working skills alongside content knowledge (Savery, 2006). As discussed in both Marra (2012) and Angouri and Locher's (2012) exploration of workplace contexts, graduates need to know 
how to disagree effectively - and to adhere to implicit 'community norms' - if they are to avoid damaging frictions with their colleagues (Marra, 2012, p.1580). The moderate presence of what has been termed task conflict - involving differences of opinion about a task - may even contribute to group performance (Jehn \& Mannix, 2001). Rather than seeking to avoid conflict, therefore, it has been argued that students perceive disagreement and having heterogeneous groups as helping to attain learning goals (Almajed, Skinner, Peterson \& Winning, 2016). What is required, however, is support in terms of enabling students to develop the skills to manage knowledge conflicts in interaction. Disagreement is thus implicitly part of the theoretical and pedagogical structure of problem-based learning, but to date there is no research that examines how disagreements are enacted in PBL tutorials.

One of the major contributions of this study is to provide an insight into the interactional management of disagreements within tutorless PBL, where detailed and systematic analyses of knowledge disagreements are most needed if we are to inform educational interventions. In doing so, we aim to build toward a cataloguing of the different ways in which disagreements are formulated in academic group situations. We define knowledge disagreements as those instances in which a speaker works against the prior speaker's assertion about a claim to knowledge, showing a lack of explicit agreement. Specifically, our research question was: how are knowledge disagreements formulated in PBL tutorials in which there is no tutor present?

\section{Method}

\section{Data collection}

The data comprises 24 video-recorded student tutorials, totalling 30 hours, from the third year of an undergraduate Chemical Engineering programme in a Scottish university. This was the students' first experience of problem-based learning as a pedagogical approach in this university programme. The tutorials were recorded between 2015-2017, and involved 23 native English speakers in total, with around 4-7 participants per tutorial group (6 groups in total). Each tutorial was recorded in a separate room on the university campus, during usual teaching hours, without a researcher present. The study was granted ethical approval, and participants provided full written consent prior to data collection. Data is in British English.

\section{Analytical procedure}

The recorded data were initially transcribed to first pass, with coded sections transcribed in more detail according to Jefferson transcription features (Jefferson, 1984). Conversation analysis was used as the analytical approach, to enable a focus on the structure and organisation of disagreement sequences in institutional interaction. The full data corpus was searched for instances where a statement, question or assertion of knowledge by one speaker was followed by a lack of alignment by any other speaker: either the absence of agreement or the presence of a disagreeing component. As noted earlier, a lengthy silence or delayed response by the second speaker may be indicative of disagreement (Pomerantz, 1984a; Kuo, 1994), and so it is necessary to consider both absences and presences in the responses. The extracts were scrutinised for consistency, ensuring that they were representative of the wider data corpus. Finally, deviant cases were drawn from the data corpus - essential in bolstering the documented implicit conversational norms (Heritage, 2012) - and in turn, this led to further, evolving analytical issues for discussion. The final body of analytical extracts were selected according 
to those instances in which there is a knowledge disagreement, rather than a disagreement regarding the task or social relationships, for instance.

\section{Analysis}

Before considering the disagreements, we briefly consider some examples of knowledge agreements from our corpus to provide a point of comparison. These are structurally uncomplicated, where the act of 'doing' agreement is achieved without delay (Rendle-Short, 2015), as shown in extract 1:

\section{Extract 1.}

1. Paul: group expectations again

2. Clare: we need to tackle this much (.) more: efficiently

3. Paul: absolutely

Here, Paul proposes an agenda ("group expectations again", line 1) which is validated by Clare ("we need to tackle this", line 2), where she establishes this as a collective group concern (the "we" personal plural) and one which must be addressed "much (.) more: efficiently". Paul's strong agreement token ("absolutely", line 3) finalises the agreed agenda, and thus, the topic is developed (Johnson, 2006).

Students in our data corpus often referenced the avoidance of task complexity as a means of attaining group agreement, also:

\section{Extract 2.}

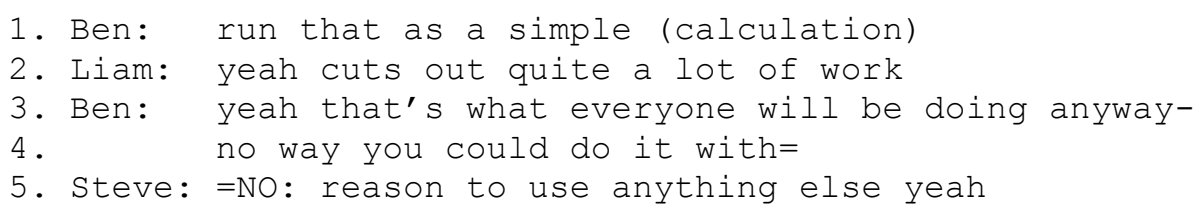

In this extract, the extreme-case formulation ("no way you could", line 4) and "NO: reason" (line 5) characterise the notion of straying from simplicity as indisputably holding negative consequences (Pomerantz, 1986). The recurring "yeah" utterances throughout this clip establish speaker alignment and ensure that silence - often an indicator of conversational trouble (Kuo, 1994) - is avoided. The agreement sequences as seen in our data corpus are commonly characterised as unambiguously agreeing, fast-flowing, and often intensified in form. These serve as a way of contrasting the different formulations of disagreements, as detailed next.

Despite critical discussions being an expected part of academic group work (particularly for PBL tutorials), disagreements were most commonly found in our corpus in a softened format, with students resisting authoritative positions. Whilst there is some degree of overlap between the categories, Table 1 details the different types of knowledge disagreement formulations that were identified in the data corpus, alongside previous research which notes similar formulations.

Table 1. Knowledge disagreement formulations identified in the data corpus 


\begin{tabular}{|c|c|}
\hline DISAGREEMENT FORMULATIONS \& EXAMPLE REFERENCES & FREQUENCY \\
\hline $\begin{array}{r}\text { Agreement-prefaced disagreements } \\
\text { - "yes, but then... no" (Pomerantz, 1984a; Mulkay, 1985; Antaki, 1994) } \\
\text { knowledge appreciations "I see what you mean... but" (Hayashi, 1996; Johnson, } \\
\text { 'I think so... but' (Hosoda \& Aline, 2015) }\end{array}$ & 46 \\
\hline $\begin{array}{l}\text { Invoking physical resources } \\
\text { " "but it says on the worksheet" (Sharma, 2012) }\end{array}$ & 24 \\
\hline $\begin{array}{l}\text { Referencing external expert (tutor) } \\
\text { •"but she said it was X" (Sharma, 2013) }\end{array}$ & 18 \\
\hline $\begin{array}{l}\text { Referencing external (non-tutor) sources } \\
\text { TOTAL said there are X" (Sharma, 2013) }\end{array}$ & 13 \\
\hline
\end{tabular}

We now illustrate examples of these disagreement formulations and focus on the way in which knowledge is managed by the students, rather than with the sequential resolving of the disagreement (e.g. Waring, 2001).

\section{Agreement-prefaced disagreements}

The most prevalent formulation of disagreement - agreement-prefaced disagreements - took various forms which were often extended over multiple turns in talk. In extract 3 below, for example, Paul and Megan are discussing a chemical process with the aid of a diagram that has been provided for them by the tutor:

\section{Extract 3 .}

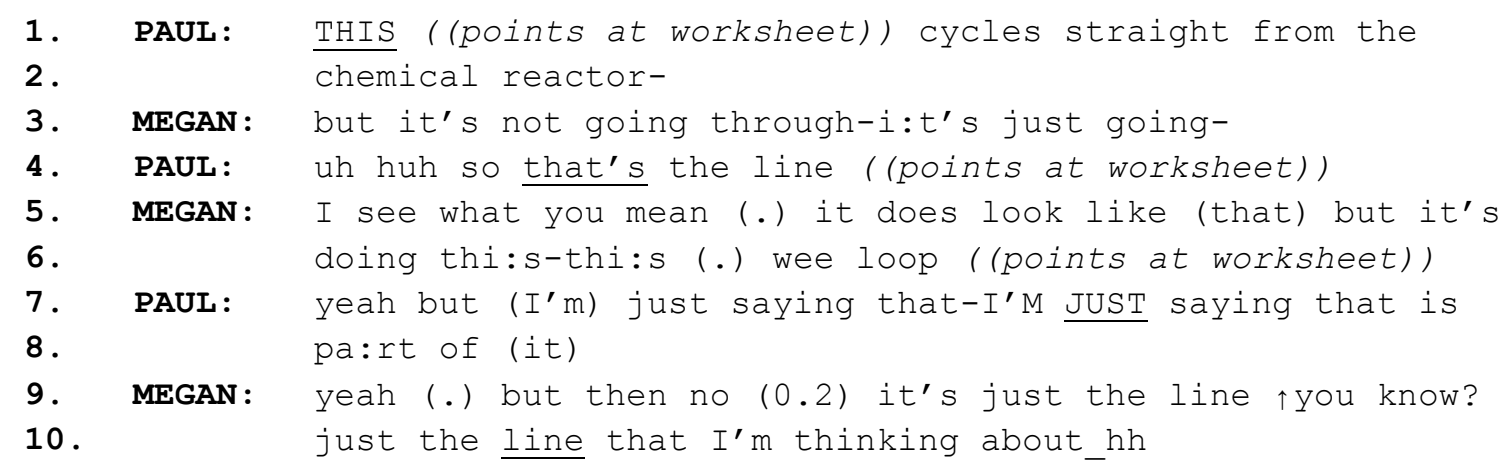

In lines 1-2, Paul makes an assertion regarding the flow of chemicals within the provided diagram ("cycles straight from"). Megan first marks her disagreement through her interjection ("but it's not", line 3), which Paul overrides by repeating his physical gesture (line 4). In line 5 , Megan then responds with a two-part agreement sequence ("I see what you mean (.) it does look like the (that)"). This preface functions as a softener of the impending second disagreement, illuminated through the low modality of "does look like", where she justifies Paul's mistaken assumption (Turnbull \& Saxton, 1997). Once she has displayed an appreciation of Paul's stance (Hayashi, 1996), Megan then builds towards her opposition 
through the use of "but", and the repetition of "thi:s-thi:s" (line 6), which actively invites Paul to collaboratively work through their misalignment.

If we now consider Megan's turn in line 9, where she rebuts Paul's stance (lines 7-8) once more, note how she first makes agreement ("yeah"), before the transition into disagreement ("but then no"). As in lines 5-6, this preface is organised in such a way that Megan shows an appreciation of Paul's viewpoint, pauses, and then edges into her disagreement (Johnson, 2006). In the present study, this 'yes but no' formulation (Pomerantz, 1984a, Antaki, 1994) functions as another means through which disagreement can be negotiated in tutorless PBL. Therefore, rather than displaying authentic agreement, the blandness of this "yeah" token merely orients to the contextual pressures to 'save face', prior to the dispreffered talk (Stivers, 2005).

As in extract 1, this preference organisation caters to the expectancies of institutional politeness, where Megan protects her opposing stance by making a preface account beforehand (Antaki, 1994). This is later shown in line 10, in that Megan emphasises the specific point she wishes to make ("just the line"), but her use of "you know?" reaffirms their alliances; she is working with Paul, not against him. By referencing the specific location of the problem, she orients to what is 'repairable' (Drew, 1997). Intriguingly, it is worth mentioning that in line 7, Paul orients to Megan's disagreement, and constructs his own agreement-plus-disagreement formulation. Therefore, despite the assumed privileges of the first speaker, he too orients to the conversational presence for maintaining group alliances.

\section{Invoking physical resources}

In extract 4 below, Paul and Megan (in a different tutorial) are discussing a laboratory experiment that they have recently completed, and which might be relevant for their work in the current PBL activity. Whereas Paul suggests fluids as the key to the solution, Megan proposes gases. In the following exchange, we see how Megan uses a series of repairinitiators that preface a disagreement:

\section{Extract 4 .}

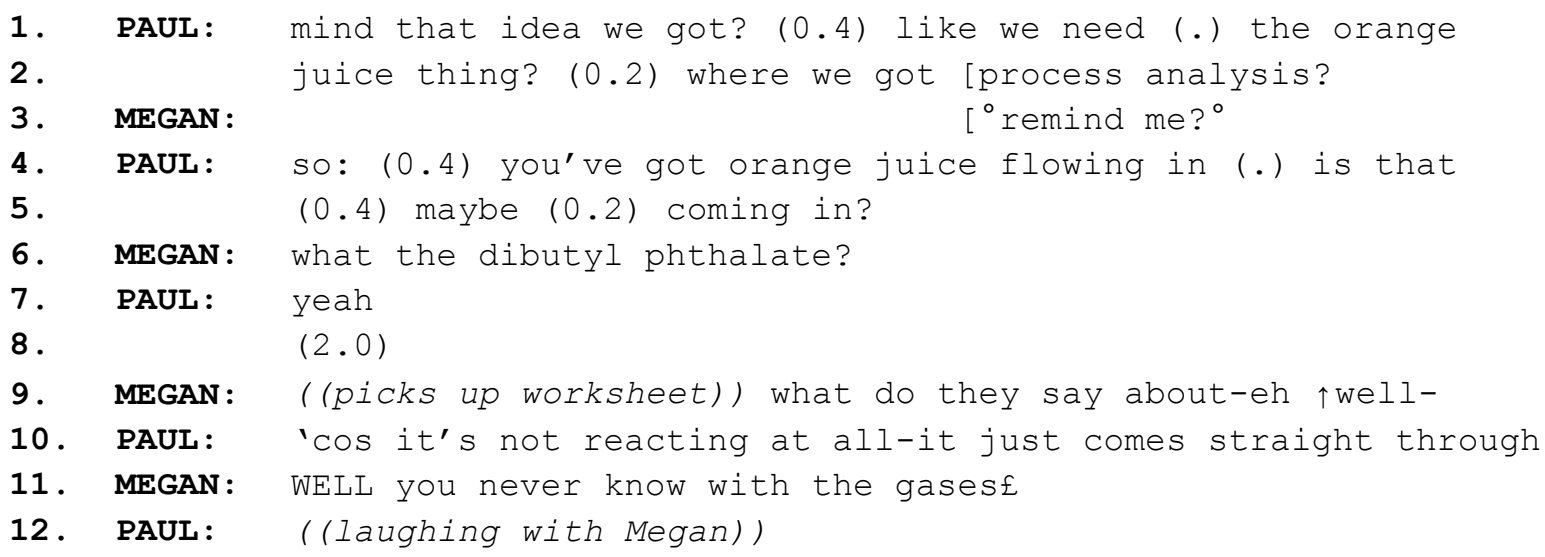

Throughout Paul's opening turn (lines 1-2), he presents a series of statements that include increasing descriptive detail, and which push toward a positive response. While not immediately aligning with these, Megan's response in line 3 - the overlapping "oremind me?" 
- functions as a repair-initiator (e.g. Pomerantz \& Heritage, 2012; Schegloff, 2007), where she quietly prompts refinement of Paul's talk. Paul's subsequent direct request for knowledge alignment ("is that (0.4) maybe (0.2) coming in?", lines 4-5) then builds towards Megan's second repair-initiator ("what the dibutyl phthalate?", line 6), and in turn, Paul's minimal response ("yeah", line 7) seems to display some conversational tensions as a result of their failure to align; also shown through the two-second silence in line 8 (Goodwin \& Heritage, 1990; Scott, 2002).

In line 9, Megan continues to divert Paul's persistent attempts to formulate agreement, but in such a way that adheres to the conversational norms for face politeness (Sifianou, 2012). For instance, rather than explicitly disagreeing with Paul, note how she engages with the PBL worksheet ("what do they say") as a prompt for their collaborative action (Day \& Wagner, 2014); explored in more depth later in the analysis. Furthermore, upon Paul's continued justification of his stance ("not reacting at all", 10), Megan's use of humour ("never know with the gases£", line 11) deflects from their misaligned views, and whilst they do not reach agreement, Paul shares in this laughter (line 12) which lightens the potential seriousness of the situation (Hendry, Wiggins \& Anderson, 2016).

In summary, as first speaker, Paul embodies a privileged interactional position and potential epistemic superiority relative to his 'listeners'; he monitors acceptable responding turns (Heritage \& Raymond, 2005; Turnball \& Saxton, 1997). Similarly, in formulating agreement, the respondent is seen as following-up the previous turn (i.e. carrying the previous speaker's knowledge forward); hence Megan's resistance here (Stivers, 2005). Therefore, through the aforementioned delay devices, agreement formulation can be avoided, while avoiding explicit disagreement with Paul. Given the social expectancies that the listener should align with the first speaker (Goodwin \& Heritage, 1990), when 'doing' disagreement, it is key that the students manage this dilemma in such a way that it does not impact their identity as a team-player.

The next extract - in which the students are discussing the necessary chemicals and boiling points involved in the problem case - builds upon the use of tutor-provided physical resources, but also shows how speakers position their 'doing unknowing' as a back-down from disagreement:

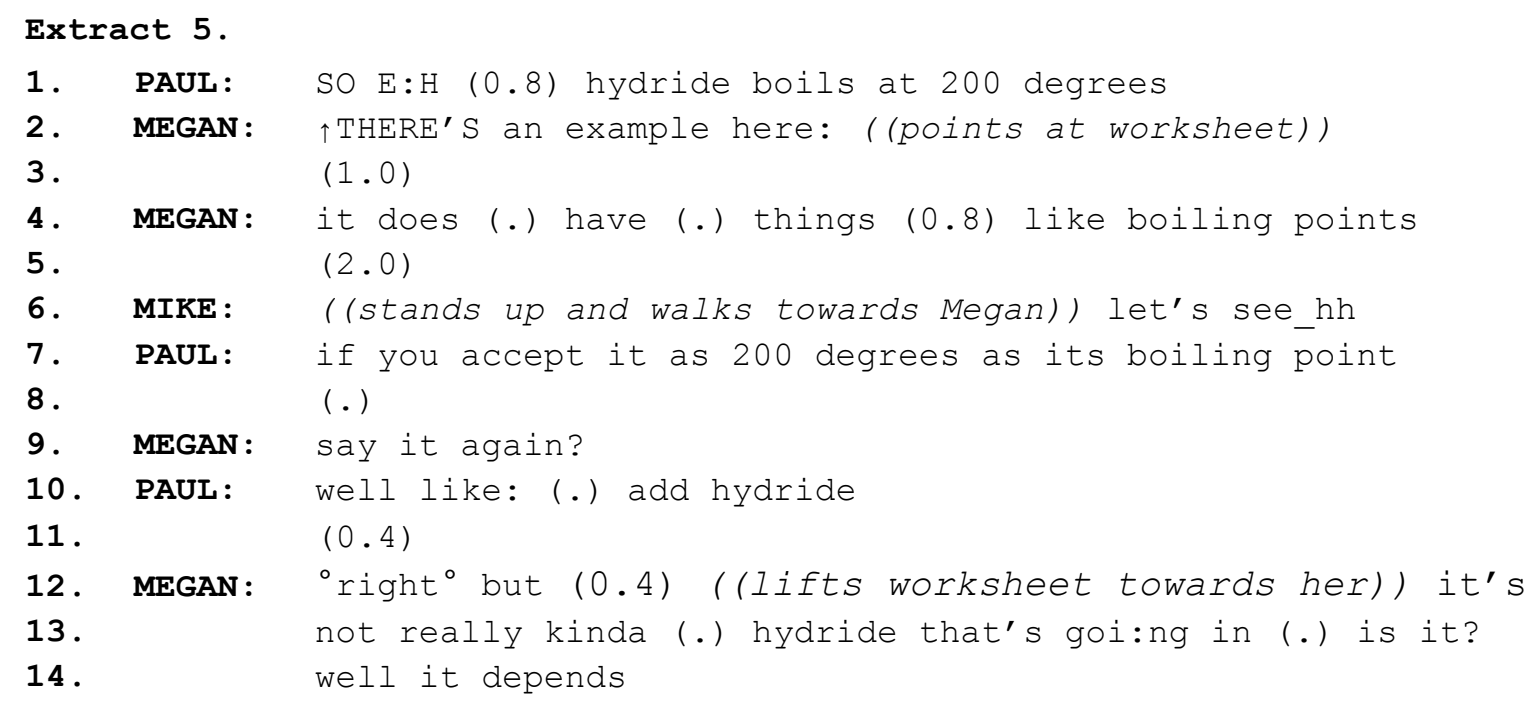


In the opening line, Paul first raises his proposal ("hydride boils at 200 degrees") but rather than formulating agreement, note how Megan's responding turn appears to deviate from the sureness of his knowledge stance. For example, by invoking the PBL worksheet, Megan prompts collaborative action, as though her peers should consider the worksheet examples before reaching a final conclusion regarding the boiling point (“个THERE'S an example here:”, line 2). However, following several prominent pauses (lines 2-5), it is group member Mike who orients to Megan's proffers ("let's see", line 6), rather than Paul making any acknowledgement of these turns.

Following Paul's second knowledge display relating to the "boiling point" (line 7) of the chemical solution under discussion, Megan applies a repair-initiator in line 9 ("say it again?"), where her query incites Paul's refinement of his opening turn ("well like: (.) add hydride", line 10). Given Megan's requests for elaboration have been fulfilled, there are increased pressures for her to offer some appreciation of Paul's stance; regardless of whether or not she agrees (Johnson, 2006). Therefore, the quietened delivery of "oright" (line 12) acts as a minimal response (and agreement preface) which 'saves face' but remains detached from authentic agreement (Stivers, 2005; Scott, 2002).

As we proceed through the extract, Megan's apparent reluctance to commit to agreement continues. She hedges around her conflicting views with very weak modality ("it's not really kinda", lines 12-13), whilst simultaneously avoiding explicit disagreement (Turnbull \& Saxton, 1997). Once Megan has made a negative assessment regarding the function of "hydride" (line 13) in the equation at hand, the succeeding tag question facilitates her alignment with Paul ("is it?", line 13). Similarly, through a mitigated "well it depends" (line 14), Megan potentially avoids appearing overly critical of her fellow team member's efforts. That is, by 'doing unknowing' (Heritage, 2012), Megan's 'vulnerability' allows her to back-down from the knowledge disagreement (Waring, 2001), instead prompting the group's collaborative reassessment of the chemical processes in question (line 15).

\section{Referencing external expert (tutor)}

The next few extracts illustrate disagreement formulations that invoke an external expert figure or source as a way to manage the knowledge claims within the discussion. Similar to those found in Sharma $(2012,2013)$ and Waring (2001), here we note how students in tutorless PBL tutorials also make use of such resources to enact a disagreement stance. In extract 6 below, for example, we see an illustration of a student referring to the tutor as being the source of the trouble. In this tutorial, the students are discussing the phases of a specific chemical process, but there is some disagreement regarding the use of equipment involved in carrying this out:

\section{Extract 6 .}

1. GARY: the: separator (0.2) it goes through some sort-form of (.)

2. $\quad$ preparation before it gets-it's a: (.)

3. LEWIS: it's not a separator (.) it's a pump

4. GARY: I KNOW BUT before it gets to there (.) 
5.

6.

7.

8.

9.

10 .

11 .

12 .

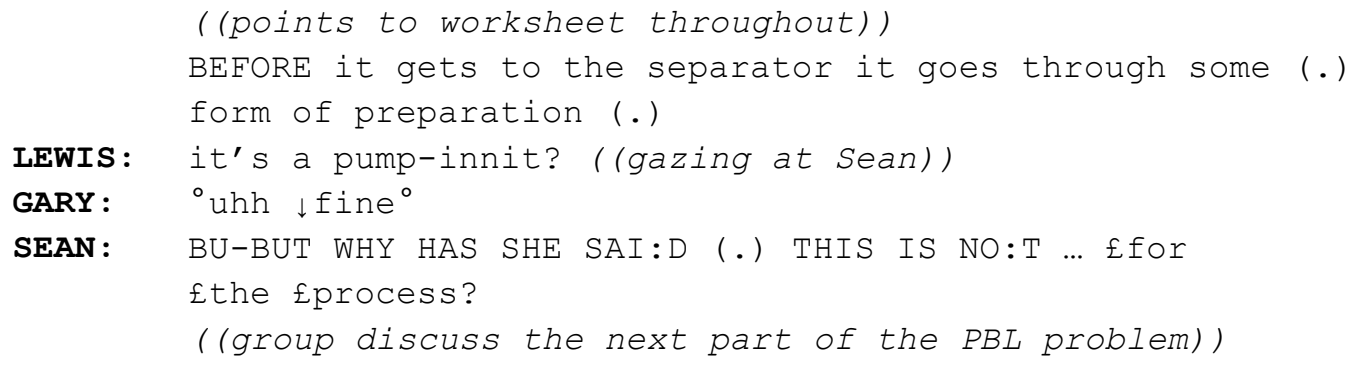

It is notable that Gary is somewhat vague in detailing his rationale for the current PBL task, where the pauses and reframes ("some sort-form"; "it gets-it's a:", lines 1-2) seem to demonstrate his struggles in formulating a solid proposal to his peers. Lewis is fairly dismissive of Gary's turn; he does not soften his disagreement ("it's not a separator", line 3) and instead presents his own knowledge stance as fact ("it's a pump"). As a result, Gary's response involves an increased level of work to get Lewis on board with his own thinking (Turnbull \& Saxton, 1997). Consequently, in line 4, Gary's agreement-with-disagreement offers an appreciation of Lewis' turn ("I KNOW"), where he gives Lewis 'what he wants to hear', prior to establishing his point once more ("BUT before it gets to there") (Sifianou, 2012). Notice how Gary also draws upon the worksheet (line 5) as an opportunity to engage his peers in this stance (Day \& Wagner, 2014), and to evidence his claims as being from a reputable source (i.e. the expert tutor) (Sharma, 2013).

In line 8, however, Gary's attempts to reach alignment with Lewis prove to be unsuccessful as Lewis repeats his disagreement once more ("it's a pump"). Furthermore, Lewis' added “innit?" tag (British slang for 'isn't it') - where his gaze is directed at Sean, rather than Gary - calls upon the support of the remaining group members in validating his stance. In turn, Gary's use of both quietened and lowered pitch ("ouhh $\downarrow$ fine ${ }^{\circ}$,, line 9) seem to be indicative of him 'surrendering his case'. In the final lines of the extract, Sean then responds to Gary's apparent dissatisfaction by establishing the fact that Gary must be incorrect, given the tutor's feedback ("WHY HAS SHE SAI:D”, line 10). In doing so, Sean detaches the group members from the blame of opposing Gary's thinking; the expert tutor figure simply cannot be wrong, and they remain guiltless in the matter (Hammar Chiriac, 2008). Sean couples these utterances with a smiley voice (“£for $£$ the process£”, lines 10-11) to further alleviate these tensions - or at least neutralise their role in this disagreement - and as shown in line 12, we see how the group very quickly progress with other matters (also shown in Hüttner, 2014 as an indirect strategy for mitigating disagreements).

Let us now consider another disagreement formulation where the superiority of the authoritative tutor is invoked as means of managing conflicting knowledge claims. During this PBL session, the students are discussing the safety regulations associated with the design of a hypothetical power plant:

\section{Extract 7 .}

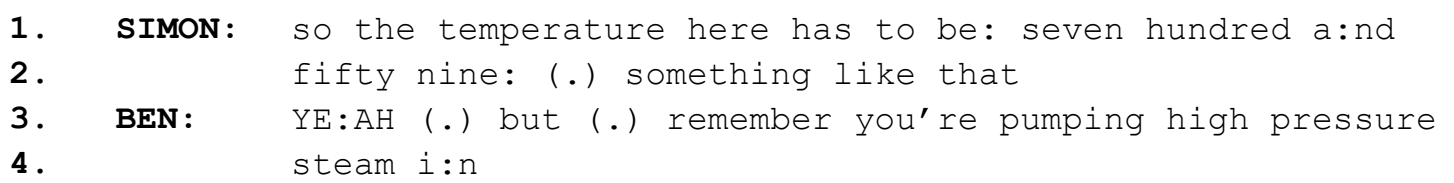


5. SIMON: this decreases in temperature

6. BEN: WELL THAT COULD MAYBE WO:RK YEAH (.) BUT I THINK 'COS she

7. said that basically heat outlet of the furnace goes into

8. a boiler ((points to worksheet))

9. SIMON: so we need that in the furnace?

Following a series of lengthy discussions relating to the construction of their power plant, in the opening lines, Simon builds towards a group conclusion ("has to be:"). Therefore, in resisting these proffers for task finalisation - a risky conversational move given it halts the goal of knowledge alignment (van der Houwen, 2009) - Ben approaches disagreement with cautiousness; firstly emphasising his appreciation of Liam's thinking ("YE:AH", line 3) before edging into his opposing stance ("but"). This is also coupled with prompts to "remember", where Ben encourages turn refinement by drawing on prior knowledge, as though Simon has merely forgotten this fragment of their previous shared learning.

However, in line 5, Simon's response (“this decreases”) does not fulfil Ben's requests, which leads to another, more explicit appreciation from Ben ("WELL THAT COULD MAYBE WO:RK YEAH”, line 6), spoken in a loud and clear voice. In doing so, Ben displays a polite acknowledgement of Simon's stance, but does so in a way which communicates low modality, allowing him to proceed - once more - with alternative suggestions ("BUT I THINK", line 6). As in the previous extract, it is at this point where Ben becomes more strategic in the legitimisation of his disagreement ("cos she said that basically", lines 6-7). By referencing the tutor ("she"), Ben invokes a dominant leadership figure, and thus, Simon has no grounds to simply override him (Sharma, 2013). Furthermore, by invoking the worksheet, Ben also projects blame onto the tutor, and in turn, positions himself as merely relaying the knowledge (Heritage, 2012). In this way, Ben achieves the upper-hand in the knowledge discrepancy - that is, he indirectly disproves Simon's point - without threatening group alliances.

\section{Referencing external (non-tutor) sources}

The final extract illuminates how members also invoke students out-with their group, and of a high academic calibre, as a means of enacting disagreement stances. In this particular session, having previously divided their PBL duties individually, it is group member Callum's turn to report his findings to his peers:

\section{Extract 8 .}

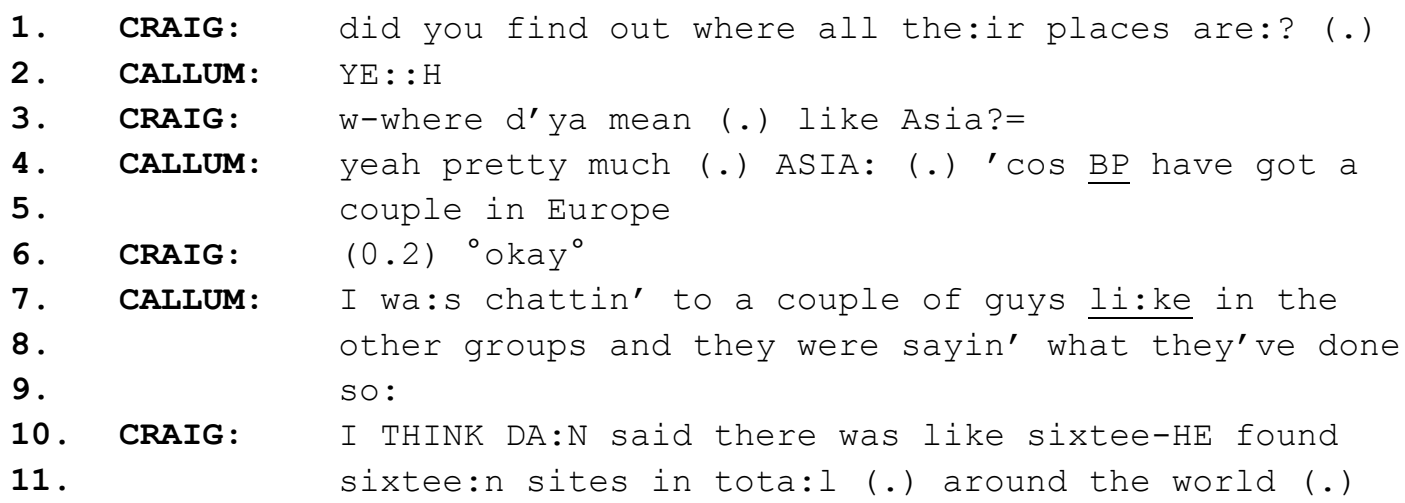


12 .

13. CALLUM:

14. CRAIG:

15. CALLUM:

16. CRAIG: think that is a fa:ir

yeah $=$

=amount of places

there's a fair amount >but I didn't really know<

$\mathrm{E}: \mathrm{MM}$ (.) who's next?

Craig's opening turn positions Callum's answer as one which involves detailed knowledge ("where all the:ir places are:?"). In line 2, however, Callum's response does not fulfil these expectancies, where he delivers only a minimal response ("YE::H"), as opposed to any tangible solutions to the problem (i.e. the full list of plant locations) (Goodwin \& Heritage, 1990). Craig orients to this inadequacy in line 3 by working to extract ("w-where d'ya mean") the desired knowledge ("like Asia?"; a descriptive proffer) from Callum. However, in lines 4-5, Callum merely confirms Craig's suggestion ("ASIA") and continues his vague stance ("pretty much") which only loosely ("got a couple") addresses the question at hand. This lack of progress is problematic, as shown through Craig's own quietened minimal response (" ookay ", line 6) (Drew, 1997).

In line 7, following Craig's unsuccessful 'fact checking' (van der Houwen, 2009), Callum is more resourceful in fighting his case, referencing his consultation with other students ("I wa:s chattin' to a couple of guys") as an assurance that his contributions are adequate ("they were sayin' what they've done so:", lines 8-9). Rather than satisfying Craig's requests, however, Callum enables a competitive culture, which proves to be detrimental to his defence. In line 10, for instance, Craig invokes his own knowledge source ("I THINK DA:N said"); a studious and high-performing classmate, known to each of the group members. In contrast to the ambiguity of Callum's "couple of guys", therefore, by drawing upon Dan's superiority, Craig overrules Callum's weak justification, positioning what Callum should have found "in tota:1 (.) around the world" (line 11).

In the final lines of the extract, Callum can no longer avoid accountability for his lack of preparation, where his agreement ("yeah", line 13) orients to the fact that both Craig and Dan cannot be wrong. Callum accepts his knowledge discrepancies ("there's a fair amount", line 15), where he downgrades his previous justifications, and then veers towards an 'unknowing' stance (Heritage, 2012); in this instance of 'deadlock', Callum uses his vulnerability to back-down from the disagreement ("but I didn't really know", line 15) (Waring, 2001). However, rather than Callum's discourse being treated as an authentic 'call for help', his failure to contribute to the group is established, and - similar to the finale of extract 6 - they promptly proceed with other matters (line 16).

\section{Discussion}

The current analytical findings align with previous CA research centring on classroom disagreements (e.g. Hosoda \& Aline, 2015; Tainio, 2011), as well as making an integral contribution to our understanding of student interactions within tutorless PBL tutorials. Specifically, it is the first known study to shed light on the expression of disagreements within a pedagogical context which expects learners to challenge their own and their peers' knowledge and understandings, without tutor participation. The opening of the analysis displays the relative simplicity of 'doing' agreement, where knowledge alignment is the preferred action in fostering group togetherness. In contrast, the rest of the analysis details the intricacy of 
disagreement formulations, where oppositional stances were frequently accompanied by agreement particles (e.g. Pomerantz, 1984a) in the form of prefaces (e.g. "yeah... but no") and knowledge appreciations (e.g. "I see what you mean... but"), as well as repair-initiators (e.g. "say that again?") and minimal responses. In this way, students subtly negotiated knowledge disagreements, rather than formulating outright rejections of peer stances, which would be clear face-threatening acts (Marra, 2012).

Additionally, the final analytical extracts show how students invoked the 'expert' tutor figure (e.g. "but she says") and tutor-provided academic materials (e.g. "but it says on the worksheet") not only in enacting disagreements, but as a way in which they could neutralise their role in opposing a peer's knowledge stance. That is, by invoking tutor superiority - similar to a PBL group culture identified by Hammar Chiriac (2008) - students projected blame upon the educational 'system' as means of maintaining peer alliances during these (indirect) disagreements (e.g. "it's not me who's saying it"). These disagreement strategies align with previous research (Sharma, 2012;2013), but our analysis is the first to identify the use of the absent tutor as a conversational resource within a tutorless PBL context. The data corpus also presented numerous instances where interactants invoked 'intellectual' students out-with their PBL group (e.g. the case of 'high-performing' Dan in extract 8) as means of empowering their disagreement formulations. Relatedly, Waring's (2001) work showed how students would call upon one another as a means of co-constructing - and thus strengthening - their disagreeing stance.

The nature of this $\mathrm{CA}$ research is imperative as it fulfils the need for continued systematic analyses of conflict data (Leung, 2005) and PBL interactions at close range (Imafuku \& Bridges, 2016). Given its theoretical foundations (De Grave et al., 1996), it may be assumed that PBL holds disagreements as less sensitive actions than in other pedagogical contexts (i.e. that PBL is disagreement-friendly). However, as shown in the current analyses, disagreement formulations do not interactionally unfold in this way. That is, whilst disagreements were frequent occurrences throughout the corpus of PBL data, students made continual orientation to institutional politeness, where formulations were highly indirect, and avoidant of explicit form. These findings build upon previous CA work on university tutorials (e.g. Benwell \& Stokoe, 2002; Stokoe, Benwell \& Attenborough, 2013) in that students resisted displays of authority or knowledge supremacy, opting for 'regular' or 'average' identities, instead. Given the tutorless pedagogical context within the present study, we argue that students adopted these neutral conversational stances as means of avoiding the risk of being substituted for the absent tutor void (i.e. that making authoritative moves such as explicit disagreements would damage one's position as a fellow team member).

With these issues in mind, we now point to what must follow next. Firstly, in many UK universities, PBL is not implemented until the latter phases of the degree; in the current study, the third-year students were experiencing this approach for the very first time. Therefore, it is likely that their strategies for managing knowledge disagreements are different from those students who are more accustomed to the pedagogical principles of PBL, and thus, it is important to examine disagreements within different cultural contexts, and within other PBL programmes, as a means of enriching this catalogue of formulations. Secondly, if we are to better grasp disagreement resolutions in PBL, future CA work should consider how disagreements are exited in tutorless PBL, following on from, for example, Hüttner's (2014) 
CA of disagreement episodes in L2 examinations (e.g. superficial versus meaningful arguments). In turn, we propose that such 'real-life' data could be used as pedagogical tools within PBL training workshops, offering guidelines which prepare students and tutors for the interactional complexities of 'doing' disagreement. 
Almajed, Abdulaziz, Vicki Skinner, Ray Peterson, and Tracey Winning. 2016. "Collaborative Learning: Students' Perspectives on How Learning Happens." Interdisciplinary Journal of Problem-Based Learning (Purdue University Press) 10: 9.

Angouri, Jo, and Miriam A. Locher. 2012. "Theorising disagreement." Journal of Pragmatics (Elsevier) 44: 1549-1553.

Antaki, Charles. 1994. Explaining and arguing: The social organization of accounts. Sage.

Benwell, Bethan, and Elizabeth H. Stokoe. 2002. "Constructing discussion tasks in university tutorials: shifting dynamics and identities." Discourse Studies (Sage Publications Sage UK: London, England) 4: 429-453.

Cekaite, Asta, and Polly Björk-Willén. 2013. "Peer group interactions in multilingual educational settings: Co-constructing social order and norms for language use." International Journal of Bilingualism 17: 174-188.

Day, Dennis, and Johannes Wagner. 2014. "Objects as tools for talk." Interacting with objects: Language, materiality, and social activity 101-123.

De Grave, Willem S., H. P. A. Boshuizen, and Henk G. Schmidt. 1996. "Problem based learning: Cognitive and metacognitive processes during problem analysis." Instructional science (Springer) 24: 321-341.

Drew, Paul. 1997. “'Open'class repair initiators in response to sequential sources of troubles in conversation." Journal of pragmatics (Elsevier) 28: 69-101.

Edstrom, Anne. 2004. "Expressions of disagreement by Venezuelans in conversation: reconsidering the influence of culture." Journal of Pragmatics (Elsevier) 36: 14991518.

Georgakopoulou, Alexandra. 2001. "Arguing about the future: On indirect disagreements in conversations." Journal of Pragmatics (Elsevier) 33: 1881-1900.

Goodwin, Charles, and John Heritage. 1990. "Conversation analysis." Annual review of anthropology (Annual Reviews 4139 El Camino Way, PO Box 10139, Palo Alto, CA 94303-0139, USA) 19: 283-307.

Hammar Chiriac, Eva. 2008. "A scheme for understanding group processes in problem-based learning." Higher Education (Springer) 55: 505-518.

Hayashi, Takuo. 1996. "Politeness in conflict management: A conversation analysis of dispreferred message from a cognitive perspective." Journal of pragmatics (Elsevier) 25: 227-255.

Hendry, Gillian, Sally Wiggins, and Tony Anderson. 2016. "The Discursive Construction of Group Cohesion in Problem-based Learning Tutorials." Psychology Learning $\backslash \&$ Teaching (SAGE Publications Sage UK: London, England) 15: 180-194.

Heritage, John. 2012. "The epistemic engine: Sequence organization and territories of knowledge." Research on Language \& Social Interaction (Taylor \& Francis) 45: 3052.

Heritage, John, and Geoffrey Raymond. 2005. "The terms of agreement: Indexing epistemic authority and subordination in talk-in-interaction." Social psychology quarterly (SAGE Publications) 68: 15-38.

Hmelo-Silver, Cindy E. 2004. "Problem-based learning: What and how do students learn?" Educational psychology review (Springer) 16: 235-266.

Hosoda, Yuri, and David Aline. 2015. "Single episode analysis of extended conflict talk 
sequences in second language classroom discussion." Journal of Language Aggression and Conflict 3: 231-262.

Hüttner, Julia. 2014. "Agreeing to disagree: 'Doing disagreement' in assessed oral L2 interactions." Classroom Discourse (Taylor \& Francis) 2: 194-215.

Imafuku, Rintaro, and Susan Bridges. 2016. "Guest Editors' Introduction: Special Issue on Analyzing Interactions in PBL-Where to Go From Here?." Interdisciplinary Journal of Problem-Based Learning 10: 6.

Jakonen, T., and Thomas Morton. 2015. "Epistemic search sequences in peer interaction in a content-based language classroom." Applied Linguistics (Oxford Journals) 36: 73-94.

Jakonen, Teppo. 2015. "Handling knowledge: Using classroom materials to construct and interpret information requests." Journal of Pragmatics (Elsevier) 89: 100-112.

Jefferson, Gail. 1984. "On the organization of laughter in talk about troubles." Structures of social action: Studies in conversation analysis 346: 369.

Jehn, Karen A., and Elizabeth A. Mannix. 2001. "The dynamic nature of conflict: A longitudinal study of intragroup conflict and group performance." Academy of management journal (Academy of Management) 44: 238-251.

Johnson, Fiona. 2006. "Agreement and disagreement: A cross-cultural comparison." BISAL (Citeseer) 1: 41-67.

Kääntä, Leila. 2014. "From noticing to initiating correction: Students' epistemic displays in instructional interaction." Journal of Pragmatics (Elsevier) 66: 86-105.

Koole, Tom. 2010. "Displays of epistemic access: Student responses to teacher explanations." Research on Language and Social Interaction (Taylor \& Francis) 43: 183-209.

Koole, Tom. 2012. "The epistemics of student problems: Explaining mathematics in a multilingual class.” Journal of Pragmatics (Elsevier) 44: 1902-1916.

Kuo, Sai-hua. 1994. "Agreement and Disagreement Strategies in a Radio Conversation." Research on Language and Social Interaction (Taylor \& Francis) 27: 95-121.

Leung, Santoi. 2005. "Conflict talk: A discourse analytical perspective." Working Papers in TESOL \& Applied Linguistics (Columbia University Academic Commons) 2: 1-19.

Macbeth, Douglas. 2011. "Understanding understanding as an instructional matter." Journal of Pragmatics (Elsevier) 43: 438-451.

Marra, Meredith. 2012. "Disagreeing without being disagreeable: Negotiating workplace communities as an outsider." Journal of Pragmatics (Elsevier) 44: 1580-1590.

Mulkay, Michael. 1985. "Agreement and disagreement in conversations and letters." TextInterdisciplinary Journal for the Study of Discourse (Walter de Gruyter, Berlin/New York) 5: 201-228.

Niemi, Kreeta. 2014. "'I will send badass viruses." Peer threats and the interplay of pretend frames in a classroom dispute." Journal of Pragmatics (Elsevier) 66: 106-121.

Pomerantz, Anita. 1984a. "Agreeing and disagreeing with assessments: some features of preferred/dispreferred turn shapes." Chap. 4 in Structures of Social Action: Studies in Conversation Analysis, edited by J. Maxwell Atkinson and John Heritage, 57-101. Cambridge, U.K.: Cambridge University Press.

Pomerantz, Anita. 1984b. "Giving a source or basis: the practice in conversation of telling "how I know"." Journal of Pragmatics 8: 607-625.

Pomerantz, A. (1986). Extreme case formulations: A way of legitimizing claims. Human studies, 9(2-3), 219-229. 
Pomerantz, Anita, and John Heritage. 2012. "Preference." Chap. 11 in The Handbook of Conversation Analysis, edited by Jack Sidnell and Tanya Stivers, 210-28. Oxford, U.K.: Wiley-Blackwell.

Rendle-Short, Johanna. 2015. "Dispreferred responses when texting: Delaying that 'no'response." Discourse \& Communication (SAGE Publications Sage UK: London, England) 9: 643-661.

Sacks, Harvey. 1987. "On the preferences for agreement and contiguity in sequences in conversation." Talk and social organization 54: 69.

Savery, John. 2006. "Overview of problem-based learning: Definitions and distinctions." Interdisciplinary Journal of Problem-based Learning 1:3.

Schegloff, Emanuel A. 2007. Sequence organization in interaction: Volume 1: A primer in conversation analysis. Vol. 1. Cambridge University Press.

Schmidt, H. G. 1993. "Foundations of problem-based learning: some explanatory notes." Medical Education (Blackwell Publishing Ltd) 27: 422-432.

Scott, Suzanne. 2002. "Linguistic feature variation within disagreements: An empirical investigation." Text \& Talk (Mouton de Gruyter) 22: 301-328.

Sert, Olcay. 2013. “"Epistemic status check' as an interactional phenomenon in instructed learning settings.” Journal of Pragmatics (Elsevier) 45: 13-28.

Sharma, Bal Krishna. 2012. "Conceding in disagreements during small group interactions in academic writing class." Classroom Discourse (Taylor \& Francis) 3: 4-28.

Sharma, Bal Krishna. 2013. "Enactment of teacher identity in resolving student disagreements in small group peer interactions." Linguistics and Education (Elsevier) 24: 247-259.

Sifianou, Maria. 2012. "Disagreements, face and politeness." Journal of Pragmatics (Elsevier) 44: $1554-1564$.

Stivers, Tanya. 2005. "Modified repeats: One method for asserting primary rights from second position." Research on language and social interaction (Taylor \& Francis) 38: 131158.

Stivers, Tanya, Lorenza Mondada, and Jakob Steensig. 2011. "Knowledge, morality and affiliation in social interaction." The morality of knowledge in conversation (Cambridge University Press Cambridge) 3-24.

Stokoe, Elizabeth, Bethan Benwell, and Frederick Attenborough. 2013. "University students managing engagement, preparation, knowledge and achievement: Interactional evidence from institutional, domestic and virtual settings." Learning, Culture and Social Interaction (Elsevier) 2: 75-90.

Tainio, Liisa. 2011. "Gendered address terms in reproach sequences in classroom interaction." Linguistics and Education 22: 330-347.

Turnbull, William, and Karen L. Saxton. 1997. "Modal expressions as facework in refusals to comply with requests: I think I should say "no'right now." Journal of Pragmatics (Elsevier) 27: 145-181.

van der Houwen, Fleur. 2009. "Formulating disputes." Journal of Pragmatics (Elsevier) 41: 2072-2085.

Waring, Hansun Zhang. 2001. "Balancing the Competing Interests in Seminar Discussion: Peer Referencing and Asserting Vulnerability." Issues in Applied Linguistics (ERIC) 12: 2950. 


\section{Appendix}

\section{Adapted from Jefferson (1984) Transcription Convention}

(.) - A dot in a bracket indicates a pause of less than two-tenths of a second.

(0.2) - Numbers in brackets refer to pauses in tenths of a second.

CAPITALS - Indicates a sound that is louder than the surrounding speech.

${ }^{\circ}$ quieter ${ }^{\circ}$ - Degree signs indicate talk that is noticeably quieter than the surrounding talk.

Underline - Indicates emphasis on speech.

$\uparrow \downarrow-$ Pointed arrows indicate a marked rising or falling in speech intonation. Placed before the change in intonation.

$\mathfrak{f}$ - A pound sign indicates talk that is suppressing laughter or leading into a 'laugh'.

[ ] - Square brackets indicate the beginning/end of overlapping speech.

Cut- - A dash following a word indicates a cut-off sound in the speech (usually as another speaker interjects).

$=-$ Equal signs indicate continuous talk between speakers.

(()) - Words in double brackets and italicised reference non-verbal aspects of the interaction. In the present analysis, reference to physical gestures and objects are also labelled here.

$><-$ 'More than' signs enclose speech which is noticeably faster than the surrounding speech; 'less than' $(<>)$ signs label slower speech.

.h - A dot before ' $h$ ' indicates an in-breath. More ' $h$ 's = longer in-breath.

$\mathbf{h}-$ ' $\mathrm{h}$ 's without a dot before them indicate an out-breath.

:: - Colons indicate an extension of the preceding (vowel) sound. More colons = greater the stretching.

(estimation) - Words in brackets label unclear speech, where estimations have been made by the analyst. 